\title{
A Review of Different Behavior Modification Strategies Designed to Reduce Sedentary Screen Behaviors in Children
}

\author{
Jeremy A. Steeves, ${ }^{1}$ Dixie L. Thompson, ${ }^{1}$ David R. Bassett, ${ }^{2}$ \\ Eugene C. Fitzhugh, ${ }^{1}$ and Hollie A. Raynor ${ }^{3}$ \\ ${ }^{1}$ Department of Kinesiology, Recreation, and Sport Studies, University of Tennessee, 1914 Andy Holt Avenue, \\ Knoxville, TN 37996, USA \\ ${ }^{2}$ Obesity Research Center, University of Tennessee, Knoxville, TN 37996, USA \\ ${ }^{3}$ Department of Nutrition, University of Tennessee, Knoxville, TN 37996, USA
}

Correspondence should be addressed to Jeremy A. Steeves, jsteeves@utk.edu

Received 15 February 2011; Revised 24 May 2011; Accepted 26 May 2011

Academic Editor: Susan B. Sisson

Copyright ( $) 2012$ Jeremy A. Steeves et al. This is an open access article distributed under the Creative Commons Attribution License, which permits unrestricted use, distribution, and reproduction in any medium, provided the original work is properly cited.

Previous research suggests that reducing sedentary screen behaviors may be a strategy for preventing and treating obesity in children. This systematic review describes strategies used in interventions designed to either solely target sedentary screen behaviors or multiple health behaviors, including sedentary screen behaviors. Eighteen studies were included in this paper; eight targeting sedentary screen behaviors only, and ten targeting multiple health behaviors. All studies used behavior modification strategies for reducing sedentary screen behaviors in children (aged 1-12 years). Nine studies only used behavior modification strategies, and nine studies supplemented behavior modification strategies with an electronic device to enhance sedentary screen behaviors reductions. Many interventions (50\%) significantly reduced sedentary screen behaviors; however the magnitude of the significant reductions varied greatly $(-0.44$ to $-3.1 \mathrm{~h}$ /day) and may have been influenced by the primary focus of the intervention, number of behavior modification strategies used, and other tools used to limit sedentary screen behaviors.

\section{Introduction}

It is well established that excessive sedentary time, independent of too little exercise, leads to a number of negative health outcomes [1-8]. Collectively, leisure-time screen behaviors, such as television (TV), videos, DVDs, video games, and computers, have been associated with increased inactivity [9] and metabolic risk factors [10]. Children are accumulating a considerable amount of sedentary screen time, particularly TV viewing [11-13], and some are not getting adequate amounts of physical activity in their leisure time [14]. For children and adolescents, overweight and obesity have been linked to sedentary leisure-time activities [15-18].

Obesity levels in children and adolescents (aged 6 through 19 years) have tripled over the past 35 years [19]. Thirty-one percent of American children are overweight or obese (as defined as being at or above the 85th percentile for body mass index (BMI) based on the Centers for Disease
Control and Prevention Growth Charts) [20]. Strategies for decreasing the current rate of childhood obesity are needed due to the physiological and psychological health risks associated with childhood obesity [21]. Because childhood obesity tracks into adulthood [22], these health risks have the potential to be present for a lifetime.

This rise in childhood obesity has been associated with reduced levels of physical activity (energy expenditure), increased consumption of food (energy intake), or both $[13,14,23,24]$. Sedentary screen behaviors, especially TV watching, are hypothesized to contribute to weight gain by reducing opportunities for energy expenditure and increasing energy intake [25-27]. Time spent engaging in TV watching can compete with time spent in other activities that require greater amounts of energy $[18,28,29]$. Also, TV watching is often coupled with unhealthy eating behaviors (e.g., increased consumption 
of soft drinks, fried foods, and snacks) due to influential environmental cues such as food and beverage commercials and easy access to food [25, 30-32]. Thus, sedentary screen behaviors may influence both sides of the energy balance equation.

Partially due to the negative health effects of sedentary screen media, the American Academy of Pediatrics recommends limiting children's total entertainment media time to less than $2 \mathrm{~h} /$ day [33]. According to recent Kaiser Family Foundation data, the average child or adolescent ( $8-18$ years) spends an average of nearly $7 \mathrm{~h} /$ day using screen-based media (i.e., TV, movies, videogames, computer), [12] with more than half of that time spent watching TV $[12,13]$. TV watching is the most prominent leisure-time activity [3436]. In 2009, among children aged $8-18$ years, TV viewing time averaged $4.5 \mathrm{~h} /$ day [12]. Based on the results from the 2001-2006 National Health and Nutrition Examination Survey, $47 \%$ of children aged 2 to 15 years spent 2 or more $\mathrm{h} /$ day using screen-based media, and $33 \%$ of children engaged in TV/video viewing alone for 2 or more $h /$ day [13]. Secondary school-aged boys averaged more TV on weekend days than weekdays [34]. Children in primary school spend 2 to $4.5 \mathrm{~h}$ /day watching TV, and preschool children spend 2 to $2.5 \mathrm{~h}$ /day watching TV [37-39]. Childhood TV viewing habits have been associated with overweight, poor fitness, smoking, and high cholesterol levels in adulthood [40], and several studies have found that sedentary screen behaviors track more strongly from childhood to adulthood than physical activity [41-43].

The prevalence of media in children's lives and its association with obesity have prompted research on methods to reduce media consumption in children. Attempts to change leisure-time behaviors in children/adolescents have taken two primary avenues: (1) increasing physical activity, and (2) reducing sedentary screen behaviors (TV/video watching, video/computer games, and computer use, etc.). Both behaviors can affect energy balance, but reducing sedentary screen behaviors may be easier to accomplish [44]. Sedentary behaviors, like other behaviors, are shaped by the interaction of many individual factors within the broader social and environmental contexts [45]. Therefore, behavior change interventions that are theoretically based may prove more effective than atheoretical approaches [46, 47].

The results from several studies in children suggest that reducing sedentary screen time alone, or as part of a more comprehensive program, may be a promising strategy for preventing and treating obesity [48-50]. Information on different methods of reducing sedentary behaviors can help in the design of more effective interventions in this growing field of research.

Thus, the purpose of this paper is to review randomized controlled trials that have incorporated strategies for reducing sedentary behaviors in children aged 0 to 18 years. This paper examines the specific behavior modification strategies used and documents the frequency of their use in randomized controlled trials targeting a reduction in sedentary screen behaviors. We separate studies into those that focused specifically on reducing sedentary behaviors and those that focused on changing multiple health behaviors, including reducing sedentary screen behaviors. The theoretical background of the strategies used for behavior change is also listed. The different measures (self-report or electronic) used to assess sedentary behavior are highlighted. Finally, recommendations are provided regarding the types of interventions that appear to be most effective in reducing sedentary screen behaviors.

\section{Methods}

2.1. Study Criteria. This systematic review identified studies that attempted to reduce sedentary behaviors in children (1 to 12 years of age). The initial search's age range was 0 to 18 years, but no studies were identified with children outside the 1- to 12-year-old age range. Only trials intended to reduce sedentary screen behaviors were included in this paper. Studies that did not describe group assignment strategies were considered to be nonrandom in assignment and thus excluded from this paper.

For inclusion in the paper, randomized controlled trials were required to have a clear focus on reducing sedentary screen behaviors, particularly TV watching, and this reduction in sedentary screen behaviors had to be one of the reported outcomes of interest. While some studies specifically targeted TV viewing, other studies targeted TV viewing as part of reducing multiple sedentary screen behaviors. In some studies, the reduction in sedentary screen behavior was the primary objective, while in others it was measured as a secondary aim, with changes in body weight or BMI as the primary aim. Multiple behavior interventions that included reductions in sedentary behavior in addition to other modalities (diet and exercise) were also eligible for inclusion in this paper. This paper separated findings based on whether the intervention focused only on reducing sedentary screen behaviors or whether it focused on multiple health behaviors, including sedentary screen behaviors. Because the strategies and targets may be different for younger versus older children, study findings were presented by age in the Tables.

2.2. Search Strategy. A search was conducted using the PubMed database. We used a combination of Medical Subject Headings $(\mathrm{MeSH})$ and keywords. MeSH selections included such terms as Television, Motor Activity, Health Promotion/methods, Overweight/prevention and control, Overweight/rehabilitation, Overweight/therapy, Behavior Therapy, Overweight, Time Factors, Television/utilization. Keywords included sedentary, screen time, television viewing, and television watching in combination with such keywords as reduce, reduction, and limit. Results were limited to randomized controlled trials from 1985 to 2010, for children/adolescents aged $0-18$ years, and articles written in English only. One independent reviewer (J. A. Steeves) screened the titles and abstracts of all studies identified by the PubMed search to determine potentially relevant studies. In the initial step of screening, he excluded studies that did not have a reduction of sedentary screen behaviors intervention component or that did not report changes in sedentary screen behaviors 


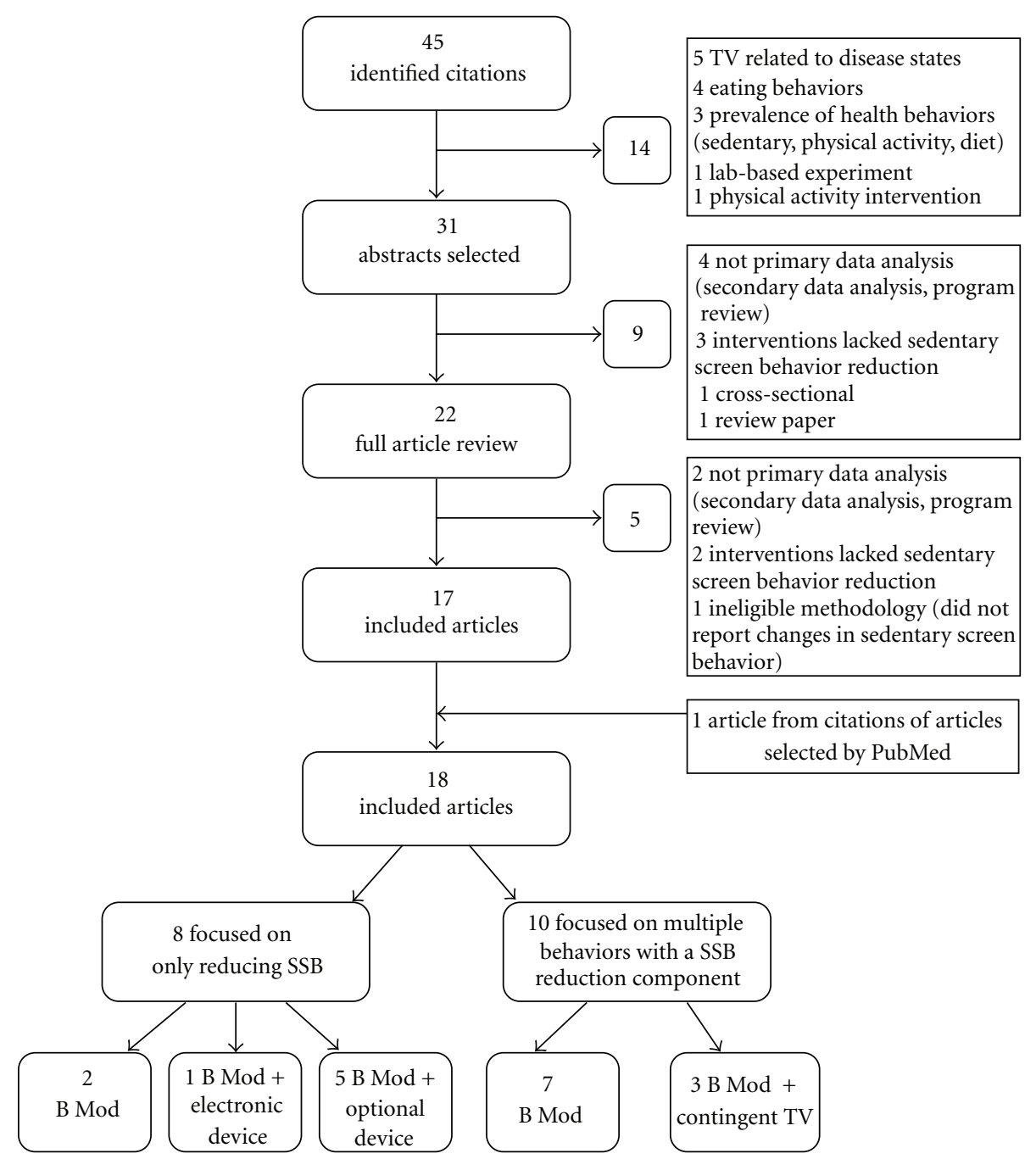

FIGURE 1: SSB: sedentary screen behavior; B Mod: behavior modification techniques.

as an outcome variable. Examples of the types of studies excluded during this initial step included the following: studies that were secondary data analysis; cross-sectional studies examining the relationship between TV viewing and eating behaviors, activity behaviors, other behaviors, or disease states; studies evaluating commercial weight-loss programs that did not involve a sedentary screen behavior reduction component; laboratory-based studies; prevalence of sedentary screen behaviors use studies. Following the initial screening process, selected articles were reviewed by J. A. Steeves. Full text articles that met all inclusion criteria were included in the paper.

\section{Results}

3.1. Identified Studies. The preliminary search of PubMed identified 45 citations, and of those, 31 abstracts were selected and reviewed. Twenty-two abstracts met the inclusion criteria and full manuscripts were examined in further detail. Upon full article review, five articles were removed for the following reasons: not primary data collection (secondary data analysis, program review) $(n=2)$; intervention did not involve a sedentary behavior reduction $(n=2)$; not reporting baseline or changes in sedentary behaviors $(n=1)$. See Figure 1 for complete rationale of exclusion. Of the initial 45 citations, 17 articles met all study criteria. One additional article, not discovered in the initial search, was added to the final selection from the citations of selected articles. A total of 18 were included for review. All studies were published between 1999 and 2010 in refereed journals. Depending on the study, sedentary screen behaviors could include: recreational screen time, TV, DVD, VHS, video games, computer games, or internet. Sedentary screen behaviors did not include educational activities such as reading or doing homework on the computer.

The 18 studies included in this systematic review measured comparable outcomes with varying methodologies. Tables 1 and 2 summarize the characteristics of studies that only focused on sedentary screen behaviors and studies 


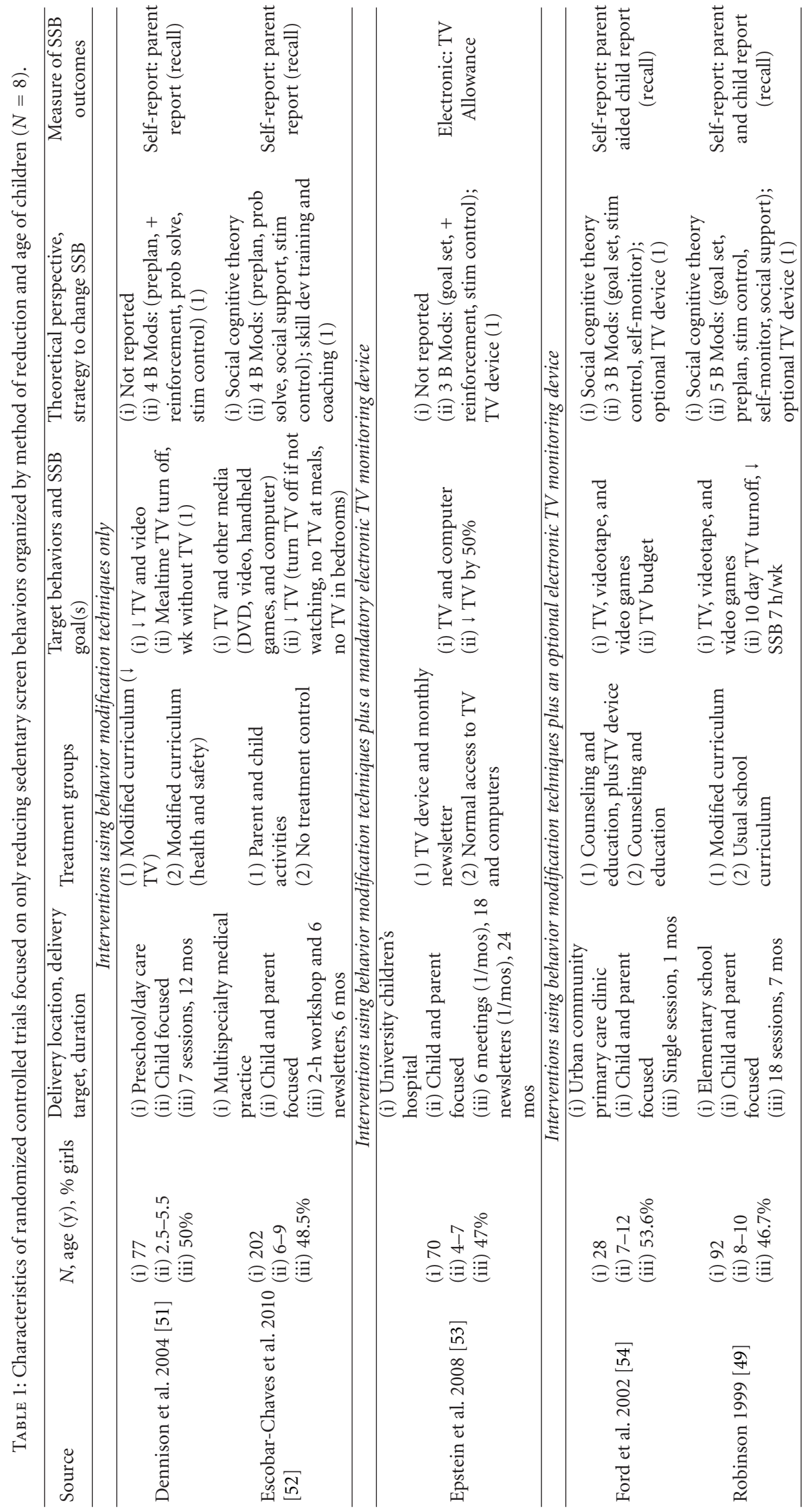




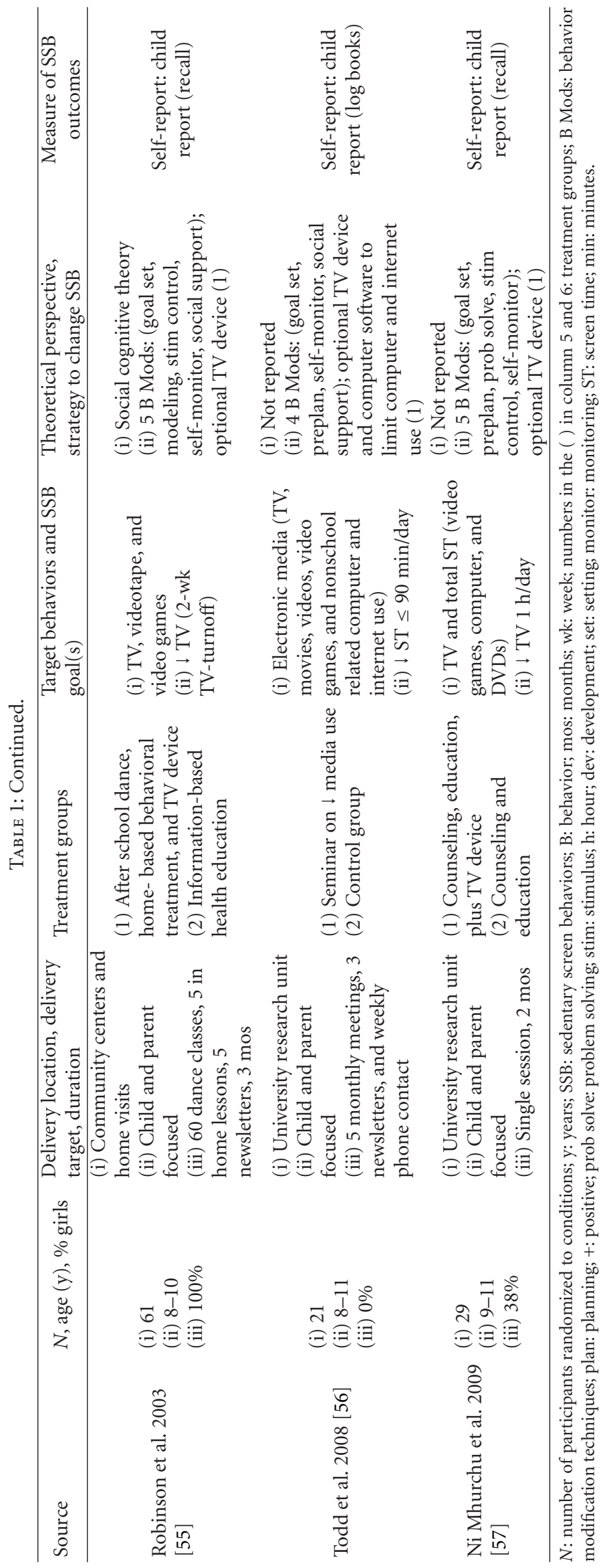




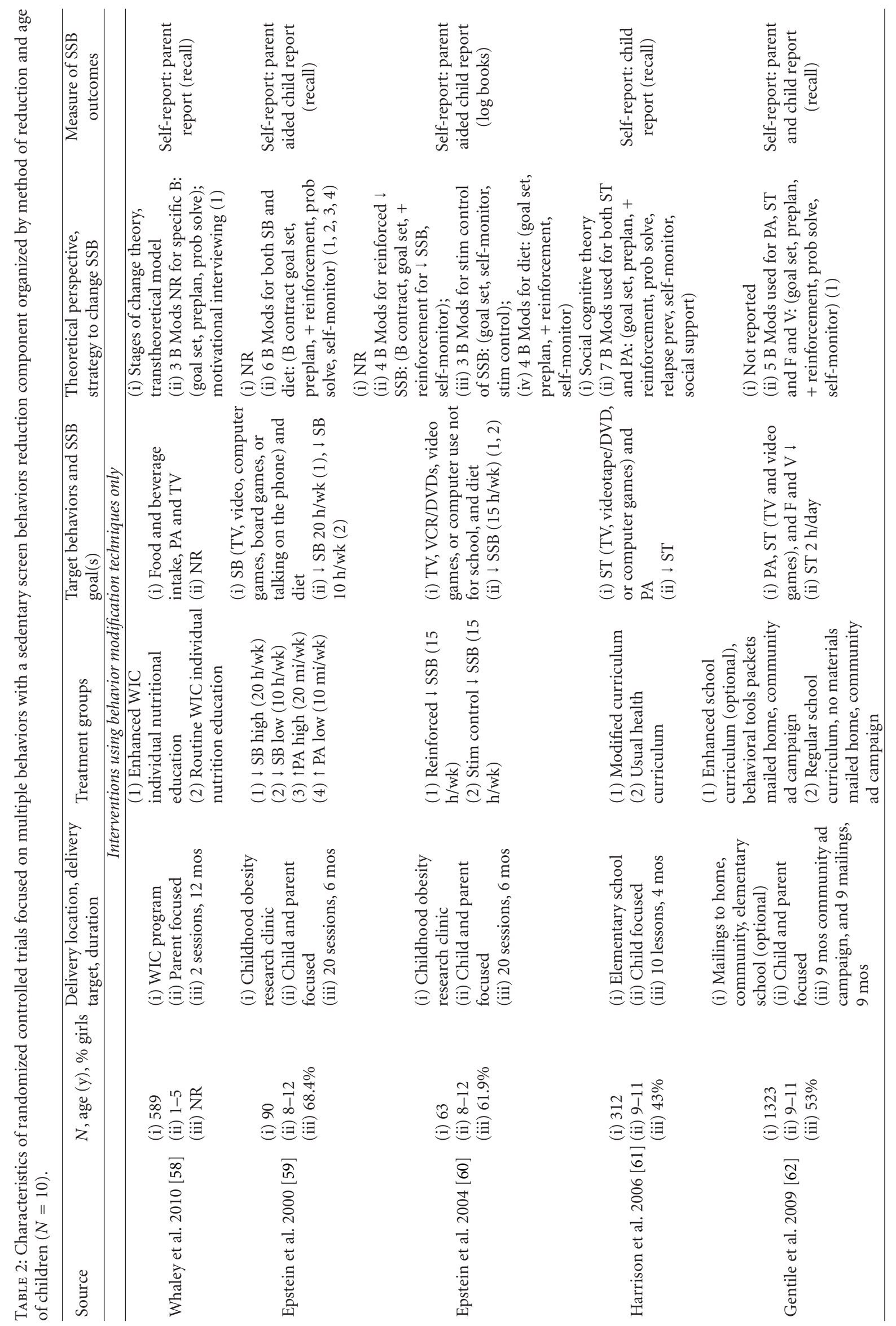




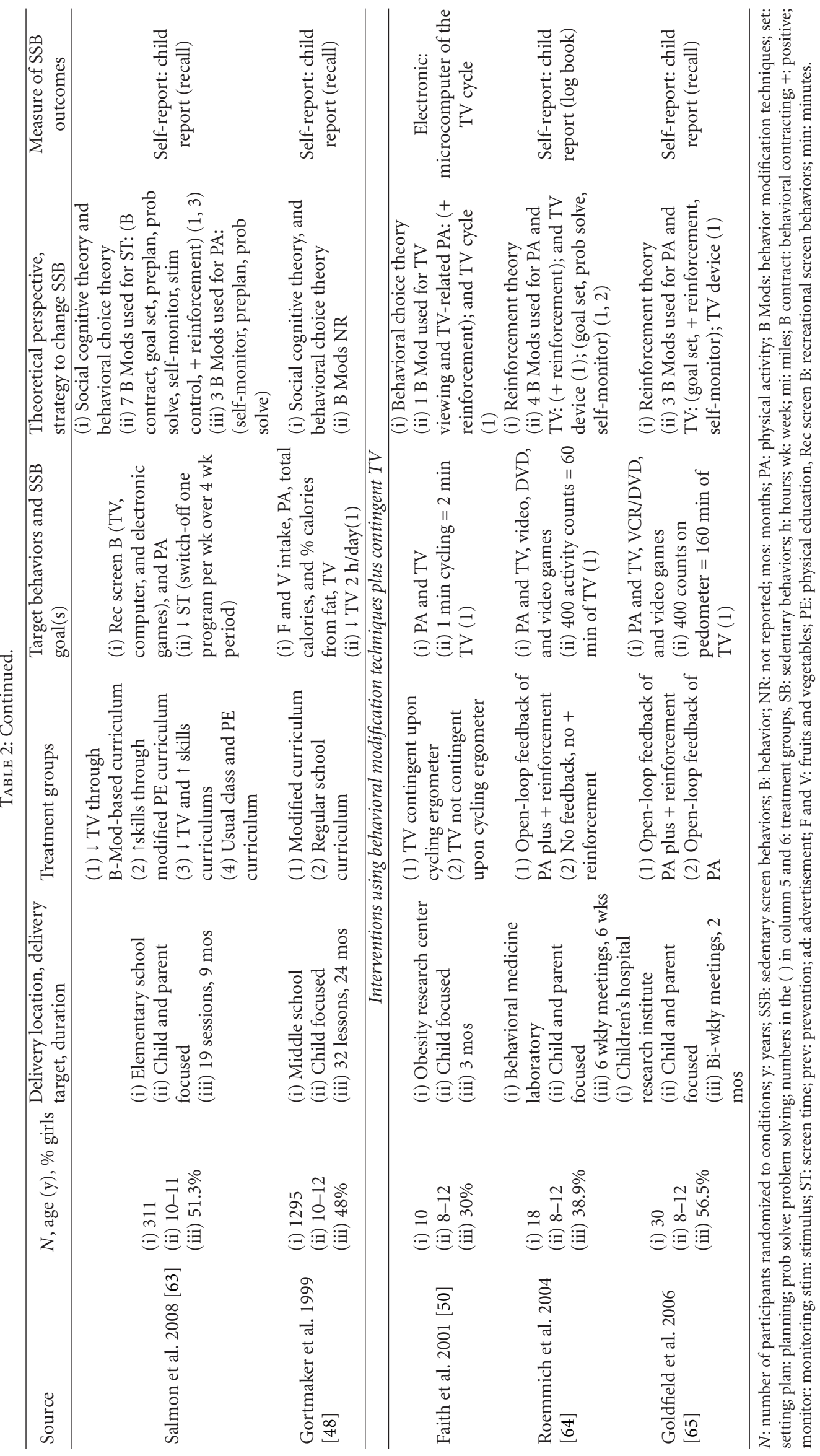


TABLE 3: Outcomes of randomized controlled trials focused on only reducing sedentary screen behaviors organized by method of reduction and age of children $(N=8)$.

\begin{tabular}{|c|c|c|c|c|c|}
\hline \multirow[t]{2}{*}{ Source } & \multirow[b]{2}{*}{ Treatment group } & \multicolumn{2}{|c|}{ Change in SSB (h/day) } & \multicolumn{2}{|c|}{$\%$ change in SSB } \\
\hline & & Intervention, mos & Followup, mos & Intervention, mos & Followup, mos \\
\hline \multicolumn{6}{|c|}{ Interventions using behavior modification techniques only } \\
\hline \multirow{4}{*}{ Dennison et al. 2004 [51] } & & $0-12$ & None & $0-12$ & None \\
\hline & 1 & $-0.44^{*}$ & & $-26 \% *$ & \\
\hline & 2 & +0.23 & & $+11 \%$ & \\
\hline & & $0-6$ & None & $0-6$ & None \\
\hline \multirow{2}{*}{ Escobar-Chaves et al. 2010 [52] } & 1 & -0.53 & & $-25 \%$ & \\
\hline & 2 & -0.53 & & $-21 \%$ & \\
\hline \multicolumn{6}{|c|}{ Interventions using behavior modification techniques plus a mandatory electronic TV monitoring device } \\
\hline \multirow{3}{*}{ Epstein et al. 2008 [53] } & & $0-24$ & None & $0-24$ & None \\
\hline & 1 & $-2.5^{*}$ & & $-72 \% *$ & \\
\hline & 2 & -0.74 & & $-20 \%$ & \\
\hline \multicolumn{6}{|c|}{ Interventions using behavior modification techniques plus an optional electronic TV monitoring device } \\
\hline \multirow{4}{*}{ Ford et al. 2002 [54] } & & $0-1$ & None & $0-1$ & None \\
\hline & 1 & -2.0 & & $-26 \%$ & \\
\hline & 2 & $-2.0^{\mathrm{b}}$ & & $-36 \%{ }^{\mathrm{b}}$ & \\
\hline & & $0-6$ & None & $0-6$ & None \\
\hline \multirow{5}{*}{ Robinson 1999 [49] } & 1:child reported & $-0.94^{*}$ & & $-43 \% *$ & \\
\hline & 1:parent reported & $-0.51^{*}$ & & $-6.5 \% *$ & \\
\hline & 2:chid reported & -0.14 & & $-28 \%$ & \\
\hline & 2:parent reported & -0.02 & & $-1.0 \%$ & \\
\hline & & $0-3$ & None & $0-3$ & None \\
\hline \multirow{3}{*}{ Robinson et al. 2003 [55] } & 1 & -0.41 & & $-15 \%$ & \\
\hline & 2 & +0.10 & & $+3.2 \%$ & \\
\hline & & $0-2.5$ & $0-5$ & $0-2.5$ & $0-5$ \\
\hline \multirow{3}{*}{ Todd et al. 2008 [56] } & 1 & $-1.2^{\mathrm{b}}$ & -1.18 & $-47 \%{ }^{\mathrm{b}}$ & $-46 \%$ \\
\hline & 2 & -0.63 & -1.03 & $-24 \%$ & $-40 \%$ \\
\hline & & $0-2$ & None & $0-2$ & None \\
\hline \multirow{2}{*}{ Ni Mhurchu et al. 2009 [57] } & 1 & -0.60 & & $-31 \%$ & \\
\hline & 2 & -0.01 & & $-0.8 \%$ & \\
\hline
\end{tabular}

SSB: sedentary screen behaviors; h: hour; treatment group: group assignment (1: treatment group, 2: control group); mos: months; *: significant difference between groups; ${ }^{\text {b: }}$ significantly different from baseline value.

that focused on changing multiple behaviors, respectively. Tables 3 and 4 summarize the changes in sedentary screen behaviors in those interventions that only targeted sedentary screen behaviors and those interventions that focused on changing multiple behaviors, respectively. Each of the tables separates the studies by the types of strategies used to change sedentary screen behaviors and then organizes studies in ascending order based upon the age of the participants, with studies with the youngest participants listed first. Tables 1 and 2 include a summary of each study documenting sample size, age, gender, location of delivery, primary target(s) of intervention delivery, duration, treatment groups, targeted behaviors and goals associated with reducing sedentary screen behaviors, theoretical perspective and strategies to reduce sedentary screen behaviors, and the method of measurement of the sedentary screen behaviors. Tables 3 and 4 summarize the study outcomes on sedentary screen behaviors. The results below provide an overview of the general characteristics and outcomes of all 18 studies.

Forty-four percent of the studies focused solely on reducing sedentary screen behaviors, with $63 \%$ of these studies having sedentary screen behavior changes as their primary dependent variable. Change in BMI was the primary dependent variable in the other 37\%. Fifty-six percent of the studies focused on changing multiple health behaviors, and either had weight change as the primary dependent variable $(40 \%)$ or had multiple primary dependent variables (obesity, BMI, physical activity, sedentary screen behaviors, diet, etc.) $(60 \%)$. Four types of sedentary screen behavior reduction interventions were identified in this paper: (1) sedentary screen behavior reduction interventions using behavior modification components $(n=9)$; (2) sedentary 
TABLE 4: Outcomes of randomized controlled trials focused on multiple behaviors with a sedentary screen behaviors reduction component organized by method of reduction and age of children $(N=10)$.

\begin{tabular}{|c|c|c|c|c|c|}
\hline \multirow[t]{2}{*}{ Source } & \multirow[b]{2}{*}{ Treatment group } & \multicolumn{2}{|c|}{ Change in SSB (h/day) } & \multicolumn{2}{|c|}{$\%$ change in SSB } \\
\hline & & Intervention, mos & Followup, mos & Intervention, mos & Followup, mos \\
\hline \multicolumn{6}{|c|}{ Interventions using behavior modification techniques only } \\
\hline \multirow{4}{*}{ Whaley et al. 2010 [58] } & & $0-6$ & $0-12$ & $0-6$ & $0-12$ \\
\hline & 1 & Not renorted & $+0.30^{*}$ & Not renorted & $+13 \% *$ \\
\hline & 2 & 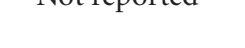 & +0.60 & 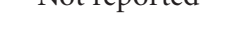 & $+26 \%$ \\
\hline & & $0-6$ & $0-24$ & $0-6$ & $0-24$ \\
\hline \multirow{4}{*}{ Epstein et al. 2000 [59] } & $\begin{array}{l}\text { (1) } \downarrow \text { SSB high } \\
(20 \mathrm{~h} / \mathrm{wk})\end{array}$ & & & $-20 \%{ }^{\mathrm{b}}$ & $-12 \%^{\mathrm{b}}$ \\
\hline & (2) $\downarrow$ SSB low $(10 \mathrm{~h} / \mathrm{wk})$ & Not reported & Not reported & $-15 \%{ }^{\mathrm{b}}$ & $-0.6 \%{ }^{\mathrm{b}}$ \\
\hline & $\begin{array}{l}(3) \uparrow \mathrm{PA} \text { high } \\
(20 \mathrm{mi} / \mathrm{wk})\end{array}$ & & & $-9.4 \%^{\mathrm{b}}$ & $-8.4 \%^{\mathrm{b}}$ \\
\hline & $\begin{array}{l}(4) \uparrow \mathrm{PA} \text { low } \\
(10 \mathrm{mi} / \mathrm{wk})\end{array}$ & & & $-6.5 \%{ }^{\mathrm{b}}$ & $-11 \%^{\mathrm{b}}$ \\
\hline \multirow{4}{*}{ Epstein et al. 2004 [60] } & & $0-6$ & $0-12$ & $0-6$ & $0-12$ \\
\hline & 1-stimulus control & Not reported & Not reported & $-2.2 \%{ }^{\mathrm{b}}$ & Not reported \\
\hline & 2-reinforced reduction & 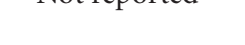 & 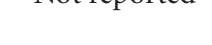 & $-2.2 \%{ }^{\mathrm{b}}$ & 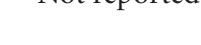 \\
\hline & & $0-4$ & None & $0-4$ & None \\
\hline \multirow{2}{*}{ Harrison et al. 2006 [61] } & 1 & -0.61 & & $-21 \%$ & \\
\hline & 2 & -0.40 & & $-13 \%$ & \\
\hline \multirow{5}{*}{ Gentile et al. 2009 [62] } & & $0-9^{\mathrm{a}}$ & $0-15^{\mathrm{a}}$ & $0-9^{\mathrm{a}}$ & $0-15^{\mathrm{a}}$ \\
\hline & 1-child reported & +0.55 & -0.11 & $+13 \%$ & $-2.9 \%$ \\
\hline & 1-parentreported & $+0.30^{*}$ & $+0.43^{*}$ & $+10 \% *$ & $+14 \% *$ \\
\hline & 2-child reported & +0.09 & -0.21 & $+2.0 \%$ & $-4.9 \%$ \\
\hline & 2-parent reported & +0.19 & +0.34 & $+5.6 \%$ & $+10 \%$ \\
\hline \multirow{5}{*}{$\begin{array}{l}\text { Salmon et al. } 2008 \text { [63] } \\
\text { (b-coefficients) }\end{array}$} & & $0-9$ & $0-12$ & $0-9$ & $0-12$ \\
\hline & 1 & $+0.55^{*}$ & $+0.57^{*}$ & & \\
\hline & 2 & +0.36 & +0.34 & Not reported & Not reported \\
\hline & 3 & +0.33 & +0.34 & & \\
\hline & & $0-24$ & None & $0-24$ & None \\
\hline \multirow{4}{*}{ Gortmaker et al. 1999 [48] } & 1-male & $-0.70^{*}$ & & $-19 \% *$ & \\
\hline & 1-female & $-0.70^{*}$ & & $-23 \% *$ & \\
\hline & 2-male & -0.35 & & $-9.3 \%$ & \\
\hline & 2-female & -0.11 & & $-3.6 \%$ & \\
\hline \multicolumn{6}{|c|}{ Interventions using behavioral modification techniques plus contingent $T V$} \\
\hline \multirow{3}{*}{ Faith et al. 2001 [50] } & & $0-3$ & None & $0-3$ & None \\
\hline & 1 & $-3.1^{*}$ & & $-95 \% *$ & \\
\hline & 2 & -0.26 & & $-9.1 \%$ & \\
\hline \multirow{4}{*}{ Roemmich et al. 2004 [64] } & & $0-1.5$ & None & $0-1.5$ & None \\
\hline & 1 & -0.33 & & Not reported & \\
\hline & 2 & +0.22 & & & \\
\hline & & $0-2$ & None & $0-2$ & None \\
\hline \multirow{2}{*}{ Goldfield et al. 2006 [65] } & 1 & $-1.9^{*}$ & & $-72 \% *$ & \\
\hline & 2 & +0.24 & & $+9.5 \%$ & \\
\hline
\end{tabular}

SSB: sedentary screen behaviors; h: hour; treatment group: group assignment (1: treatment group, 2: control group); mos: months; wk: week; mi: miles, Salmon et al. 2008 [63]; 1: $\downarrow$ TV through behavioral modification based curriculum, 2: $\uparrow$ skills through modified physical education curriculum, $3: \downarrow$ TV and $\uparrow$ skills curriculums); ${ }^{*}$ : significant difference between groups; ${ }^{\text {a }}$ : Significant difference in reported TV viewing time between parents and children; ${ }^{b}$ significantly different from baseline value. 
screen behavior reduction interventions with behavioral modification plus optional use of an electronic TV monitoring device $(n=5)$; (3) sedentary screen behavior reduction interventions that used behavioral modification and mandatory use of an electronic device that limited screen time $(n=1)$; (4) sedentary screen behavior reduction interventions with behavior modification plus contingent TV (i.e., access to TV was based upon completing certain tasks or exercising for a certain amount of time) $(n=3)$.

While the majority $(61 \%)$ of these behavior change intervention strategies were theoretically based, 39\% of reviewed studies did not report the theory upon which they were based $[51,53,56,57,59,60,62]$. Of all the studies, $27 \%$ of intervention strategies were based on social cognitive theory $[49,52,54,55,61], 11 \%$ were grounded on both social cognitive and behavioral choice theory [48, 63], 11\% were based on reinforcement theory $[64,65]$, one $(6 \%)$ was based on behavioral choice theory [50], and one (6\%) was based on the transtheoretical model [58].

The ages of the children included in these studies ranged from 1 to 12 years. Eighty-three percent of the studies targeted children between the ages of 6 and 12 years [48$50,52,54-57,59-65]$, with $72 \%$ targeting children between the ages of 8 and 12 years [ $48-50,55-57,59-65]$. Two studies $(11 \%)$ included children aged 1 to 5 years exclusively $[51,58]$, and one study (6\%) included children aged 4 to 7 years [53]. Eighty-eight percent of the studies included both male and female participants. One study $(6 \%)$ included only males [56], and one study (6\%) included only females [55]. Sample sizes ranged from 10 to 1323 participants. Study durations ranged from 1 to 24 months.

The majority (55\%) of the interventions were delivered through research centers (i.e., universities, physicians clinic, medical centers) $[50,52-54,56,57,59,60,64,65]$, or through schools or preschools $(27 \%)[48,49,51,61,63]$. One study $(6 \%)$ was delivered through the federally funded health and nutrition program for women, infants, and children (WIC) [58], one study (6\%) delivered a multilevel program (family, community, and school) [62], and one intervention (6\%) was delivered through community centers and home visits [55]. Most interventions (72\%) focused their delivery towards both the child and the parent [49, 52-57, 59, $60,62-65]$, some interventions (22\%) focused primarily on delivering the messages to the child $[48,50,51,61]$, and one intervention (6\%) focused delivery solely on the caregiver/parent [58].

Self-report (child only, parent only, and parent-assisted, or parent and child) of sedentary screen behaviors was the method used most frequently $(89 \%)$ to assess changes in behaviors. Forty-four percent of studies relied on child (ages 8-12 years) self-report (six used recall questionnaires, two used activity log books) [48, 55-57, 61, 63-65], 17\% relied on parental report (recall questionnaires) of their children's (ages 1-9 years) sedentary screen behaviors [51, 52, 58], 17\% used parent-assisted report (two used recall questionnaires, one used activity log books) of the child's (ages 7-12 years) sedentary screen behaviors $[54,59,60]$, and $11 \%$ used separate parent and child reports (recall questionnaires) of the child's (ages 8-11 years) sedentary screen behaviors [49,
62]. Two studies (11\%) used an electronic device (one used the TV Allowance, one used the TV cycle microcomputer) to record screen time usage in children (ages 4-12 years) $[50,53]$.

\subsection{Randomized Controlled Trials Focused on Only Reducing Sedentary Screen Behaviors}

3.2.1. Interventions That Used Behavior Modification Techniques Only. Two studies used behavior modification techniques alone in interventions to reduce sedentary behaviors $[51,52]$. A total of five different behavior modification techniques, preplanning, positive reinforcement, problem solving, stimulus control, and social support, were provided to the children in these two studies to help with reducing sedentary screen behaviors. Three behavior modification techniques were used in both of these studies: preplanning, problem solving, and stimulus control. Five behavioral modification strategies were used in one study [51], and Escobar-Chaves et al. [52] used four behavior modification techniques plus skill development training and coaching.

Both studies appeared to reduce sedentary screen time. One intervention successfully reduced TV viewing in the intervention group $(-0.44 \mathrm{~h} / \mathrm{day}$, or $26 \%)$ [51] when compared to the control group. The other study showed a trend towards reducing total media consumption in the intervention group $(-0.53 \mathrm{~h} /$ day or $25 \%)$ [52]. Results from these interventions suggest that when only sedentary screen time behaviors are targeted, behavioral modification strategies successfully reduce these behaviors.

\subsubsection{Interventions That Used Behavioral Modification and} Mandatory Use of an Electronic Device. One intervention used an electronic device (TV Allowance) to supplement behavior modification techniques to reduce TV viewing and computer time [53]. The TV Allowance turned off the TV and computer screens and did not allow them to be turned on again once the weekly preprogrammed amount of time was met [53]. Thus, it enforced a weekly time budget (a reduction of $10 \%$ of their baseline amount per month; up to a $50 \%$ reduction) for use of the TV and computer games. Along with the TV Allowance, three behavior modification techniques were used: goal setting, positive reinforcement, and stimulus control.

The TV Allowance and behavior modification strategies reduced sedentary screen time by $2.5 \mathrm{~h} /$ day, or $72 \%$ from baseline [53]. Combining technology with behavior modification techniques substantially reduced sedentary screen time.

3.2.3. Interventions That Used Behavioral Modification Plus Optional Use of an Electronic TV Monitoring Device. Five studies combined the use of an optional electronic TV monitoring device (i.e., TV Allowances or Token TV) with behavioral modification strategies [49, 54-57]. While the electronic TV monitoring devices were attached to participants' TVs, they were not a mandatory part of the intervention treatment. Besides setting limits, these devices 
can help participants to self-monitor TV watching [66]. In addition to the optional use of the electronic TV monitoring device provided to the families in each of these studies, a total of seven different behavior modification techniques were used to help the children reduce their sedentary screen behaviors, including: goal setting, modeling, preplanning, problem solving, stimulus control, self-monitoring, and social support. The three most frequently used behavior modification techniques used in these interventions were goal setting, self-monitoring, and stimulus control. An average of four behavior modification strategies were incorporated into these studies, with three studies using five $[49,55,57]$, one study using four [56], and one study using three behavior modification techniques [54].

Two of the five studies reported significant reductions in sedentary screen time $[49,56]$. One of the five TV reduction interventions that augmented their behavioral modification techniques with the electronic TV monitoring device reported significant reductions in TV viewing from baseline [56]. In this study, participants in the experimental group experienced a significant reduction in electronic media of $1.2 \mathrm{~h} /$ day or $47 \%$ after 10 weeks and maintained this reduction at 20 weeks (reduction of $1.18 \mathrm{~h} /$ day or $46 \%$ ) [56]. One study reported a significant reduction in TV viewing compared to the control children [49]. In these studies, the magnitude of the significant TV viewing reductions varied from $0.5 \mathrm{~h} /$ day or $0.94 \mathrm{~h} /$ day [49] to $1.2 \mathrm{~h} /$ day [56], or from $7 \%$ or $43 \%$ [49] to $47 \%$ [56] from baseline levels.

Three studies showed no significant decreases in sedentary behaviors [54, 55, 57]. One of these studies showed a trend towards a reduction in media use in an intervention that received a 5-10 minute counseling session about the problems with excessive media use, along with the TV device and behavior modification training in goal setting, selfmonitoring, and stimulus control [54]. In another study [55], although not significant, the treatment group children reduced TV media use by $0.41 \mathrm{~h}$ /day in comparison to an increase of $0.10 \mathrm{~h} /$ day in the control group. In the third study that did not reach significance [57], the treatment group decreased TV viewing by $0.60 \mathrm{~h} /$ day and the control group's daily TV viewing did not change $(-0.01 \mathrm{~h} /$ day $)$. The three studies that did not significantly reduce media use used a similar number of behavior modification strategies, but they were shorter in duration than the two that did reduce media use.

These studies indicate that behavior modification strategies combined with an optional electronic TV monitoring device may create reductions in sedentary screen time. However, the investigations did not report on the frequency of use for the electronic TV monitoring devices; thus it is not clear how much the devices influenced the outcomes in these investigations.

\subsection{Randomized Controlled Trials Focused on Multiple Behav- iors with a Sedentary Screen Behaviors Component}

3.3.1. Interventions Using Behavior Modification Techniques Only. Seven interventions focused on changing multiple behaviors related to energy balance (i.e., increasing physical activity, decreasing sedentary screen time, reducing sugar sweetened beverages, and increasing fruit and vegetable intake) $[48,58-63]$ through the use of behavior modification alone. Of these seven multiple behavior interventions, two did not report whether different behavior strategies were applied to each behavior $[48,58]$, three used all the behavior modification strategies equally to affect all behaviors of interest $[59,61,62]$, and two studies applied different behaviors modification techniques' to specific behaviors [60, 63].

Of the two studies that used different techniques for different behaviors, Salmon et al. [63] used behavioral contracts, goal setting, preplanning, problem solving, selfmonitoring, stimulus control, and positive reinforcement for reducing sedentary screen behaviors. The behavior modification strategies used for increasing physical activity included: self-monitoring, preplanning, and problem solving. Epstein et al. [60] compared two different methods to reduce sedentary screen behaviors. One group was reinforced for reducing their sedentary screen behaviors and used behavioral contracts, goal setting, self-monitoring, and positive reinforcement for reducing sedentary behaviors. The other group received training in goal setting and self-monitoring and used stimulus control to reduce sedentary screen behaviors. Both groups used the following behavior modification techniques to help change their diet: goal setting, preplanning, positive reinforcement, and selfmonitoring [60].

A total of nine different behavior modification techniques were provided to the children in these studies to help with reducing sedentary screen behaviors and included: behavioral contracts, goal setting, pre-planning, positive reinforcement, problem solving, relapse prevention, stimulus control, self-monitoring, and social support. The most frequently used behavior modification techniques were goal setting, positive reinforcement, preplanning, problem solving, and self-monitoring. The average number of behavior modification techniques used in these studies was five. Two studies used a total of seven behavioral modification strategies $[61,63]$, and there were three other studies that used four or more strategies [59, 60, 62]. One study did not report the behavior modification techniques they used [48], and another study did not specify what behavior modification techniques were used towards what health behaviors [58].

Three of the seven studies showed significant reductions in sedentary screen time $[48,59,60]$. One of the seven interventions was successful in reducing sedentary screen behaviors in the intervention group $(-0.7 \mathrm{~h} /$ day or $-19 \%$ in males, and $-0.7 \mathrm{~h} /$ day or $-23 \%$ in females) compared to the control group $(-0.35 \mathrm{~h} /$ day or $-9.3 \%$ in males, and $-0.11 \mathrm{~h} /$ day or $-3.6 \%$ in females) [48]. Two of the seven interventions reported significant reductions $(-2.2 \%$ to $-20 \%$, resp.) in targeted sedentary behaviors from baseline in their intervention groups $[59,60]$. Epstein et al. [59] observed a significant decrease in targeted sedentary behaviors in both the low- and high-dose treatment groups for the decrease sedentary activity at 6 months $(-15 \%$ and 
$-20 \%$, resp.). The low (10 h/wk) and high (20 h/wk) doses for decreases in sedentary behavior differed in the degree of behavior change required. At the 24-month followup, the high dose decrease in sedentary-behavior group sustained the reduction better than the low-dose decrease in sedentary behavior group $(-12 \%$ and $-0.6 \%$, resp.). In another study [60], obese children significantly and equally decreased sedentary behaviors $(-2.2 \%)$ when receiving treatment that involved either stimulus control or reinforcement to reduce sedentary screen behaviors. Among these three studies, the magnitude of the significant TV viewing reductions varied from $-2.2 \%$ [60] to $-23 \%$ [48] from baseline levels.

Four studies showed no decreases in sedentary behaviors [58, 61-63]. One study targeting parents showed that children in the intervention group watched half as much TV post intervention as children whose parents were in the control group [58]. One study showed no significant change in screen time in intervention schools [61]. According to another study, there were no changes in sedentary behaviors immediately after intervention or at the 6-month followup in either group [62]. A final study showed that the children who were in the behavioral modification treatment group reported greater TV viewing at every assessment point, compared with controls [63]. There did not appear to be any relationship between the number of behavior modification strategies used and the degree of reduction success.

Although some studies were successful at reducing sedentary screen behaviors among children, the reductions were highly variable. Also, the majority of studies did not find significant reductions in sedentary screen time. It is important to note that none of these studies had reducing sedentary screen time as the only primary dependent variable. Sixty-seven percent of these studies had changes in weight as the primary dependent variable, with changes in sedentary screen behaviors, physical activity, and diet as secondary dependent variables. The remaining $33 \%$ of these studies had multiple primary dependent variables (e.g., food and beverage consumption, physical activity, TV, sedentary screen time BMI, weight).

3.3.2. Interventions That Used Behavior Modification Plus Contingent TV. Contingent TV (where TV viewing is contingent upon performing certain tasks) has been used in three studies, in addition to behavior modification techniques, as a strategy to help reduce the amount of time children spend watching TV $[50,64,65]$. In these studies, children's targeted behaviors were rewarded by gaining access to TV, based upon completing certain tasks or for exercising for a certain amount of time $[50,64,65]$. One of the initial contingent TV studies [50] provided immediate access to TV viewing by having the child ride a stationary exercise bike attached to the TV (closed-loop system). The children could not watch TV unless they were pedaling the bike. This closed-loop system does not require any action by, or interaction with, another human. The system itself is set up to directly sense the output from the subject and then deliver the appropriate intervention or reinforcer [67]. More recent studies $[64,65]$ have used an open-loop system. In these studies, the open-loop system provides children the freedom to choose when they use the TV time they have earned as a result of performing a certain amount of physical activity $[64,65]$. In addition to contingent TV, a total of four different behavior modification techniques were used to help the children reduce their sedentary screen behaviors: goal setting, positive reinforcement, problem solving, and self-monitoring. Positive reinforcement, with TV viewing serving as the reward, was the most frequently used behavior modification technique, followed by goal setting and selfmonitoring. On average three behavior modification strategies were incorporated into the treatments of each of these studies. One study used four [64], one study used three [65], and one study used one behavior modification strategy [50].

Two contingent TV interventions reported significant reductions in TV viewing, which varied from $1.9 \mathrm{~h} /$ day [65] to $3.1 \mathrm{~h} /$ day [50], corresponding to a $72 \%$ [65] to $95 \%$ [50] reduction. In the third study, although the treatment group reduced TV viewing by $0.33 \mathrm{~h} /$ day, and the control group increased TV by $0.22 \mathrm{~h} /$ day, there was no significant difference in the changes between groups [64]. A contingent TV setup combined with behavior modification appeared to be a highly effective method to reduce TV viewing during the intervention.

\section{Discussion}

This paper demonstrates that various strategies can successfully reduce sedentary screen behaviors in children. Every identified study used behavior modification techniques. Thus, regardless of what theoretical framework was used for reducing sedentary screen behaviors, behavior modification strategies were always included in the intervention. The number of behavior modification strategies used to reduce sedentary screen behaviors varied from one to seven across these 18 studies. The more an intervention depended solely on behavior modification strategies to change sedentary screen behaviors, the greater the number of behavior modification strategies used. The behavior modification strategies cited most frequently were goal setting ( $78 \%$ of studies) and self-monitoring (67\% of studies) of progress towards reducing sedentary screen behaviors. Preplanning, problem solving, and positive reinforcement were three additional behavior modification strategies used frequently. The nine studies that incorporated other methods (electronic TV monitoring devices or contingent TV devices) to elicit a reduction in sedentary screen behaviors used fewer behavior modification techniques. While the interventions that used electronic devices and contingent TV were the most effective in decreasing TV viewing time, these studies were shorter in duration and had smaller sample sizes. Slightly more than half of the studies focused on changing multiple behaviors. Most of these studies applied all the behavior modification strategies to all behaviors. A key challenge in reviewing the results of interventions that used multiple behavior modification techniques, even when only one behavior was being intervened upon, was to document and track 
the extent to which children utilized the specific behavior modification technique(s) that were provided and determine which technique(s) were most effective at creating behavior changes [62].

Individuals typically do not change their activities or behaviors when they are simply told to do so [68]. Interventions to reduce sedentary screen behaviors have used a number of theories and strategies for behavior change. Most studies reported having a theoretical foundation. Two of the key theoretical approaches, social cognitive theory [69] and behavioral choice theory $[70,71]$, were used in $44 \%$ of the studies. These theories share the belief that behaviors may be learned from observing others and that changes in behaviors may be mediated or moderated by a number of individual, social, and environmental factors. Several other studies were based on the reinforcement theory known as the Premack principle [67]. These interventions used the reinforcing value of a popular, highly rated behavior such as watching TV to increase physical activity and reduce sedentary screen behavior by making TV contingent on physical activity. The stages of change theory, that is, the transtheoretical models' stages of change [72] were used in one study to assess the caregiver's readiness to act on new health behaviors as it related to their child. Caregivers were guided thru the stages so that they might engage in strategies that would assist their child in making changes.

As a whole, most of the studies were conducted with preadolescent children, with the ages of 8 to 12 years the most highly represented. Slightly more than half of the studies were conducted in research settings, and over $70 \%$ of the interventions were delivered to both the children and the parents. Thus, it is not clear how effective these interventions are for adolescents, if targeting the parent alone in children aged 1 to 12 , or delivery of the intervention from nonresearch settings would improve these outcomes.

Interestingly, two interventions which demonstrated negative results and showed an increase in sedentary screen behaviors $[62,63]$ targeted children in the oldest age group (8-12 years), focused on changing multiple health-related behaviors, and relied on behavior modification techniques alone, and although they made efforts to engage parents, there was no requirement for or assessment of actual parental engagement.

Additionally, one of the studies that showed negative outcomes was a multilevel intervention that was delivered through community media campaigns, mass mailings of newsletters to parents, and an optionally incorporated school curriculum [62]. The large-scale delivery of multiple health behavior messages may have diluted the message of reducing sedentary screen behaviors [62]. The other intervention that had an undesirable effect was a school-based program designed to reduce sedentary screen behaviors and increase physical activity. Parental involvement was solicited through a newsletter [63].

Another important difference between the investigations was methods used to assess sedentary screen behavior. Most investigations relied on self-report for assessing sedentary screen behaviors. Self-report (child only, parent only, and parent-assisted, or parent and child) of sedentary screen behaviors was the method used most frequently (89\%) to measure changes. In $44 \%$ of the studies, the children were considered responsible/old enough (ages 8-12 years) to report themselves, and $45 \%$ used some form of parental, parent and child, or parent-assisted report. In general, studies assessing sedentary screen behaviors in younger children were more likely to rely on parental report or parentassisted child report. Use of self-report surveys reduces researcher and participant burden because it is easy, less expensive, and less invasive or intrusive than placing an electronic monitoring device on all screen devices in the home. Although self-report and parental-report measures of sedentary screen behavior are commonly used, research regarding their validity and reliability is lacking [73]. The validity and the sensitivity of the different questionnaires to detect change in television viewing habits may vary by the age of the child and whether the parent or the child does the reporting [51]. Measuring sedentary screen behaviors via self-report is prone to reporting and measurement bias [57]. In households where TV provides background noise to daily activities, parent or child perceptions of "watching time" could be different [74]. In intervention studies focused on reducing TV viewing, the perception of TV being a negative behavior could cause an underreporting of viewing [74].

TV time monitors that can provide objective measures of viewing time may be suitable for some interventions [53], but using objective measurement methods may limit the number of sedentary screen behaviors capable of being monitored. Objective measures of TV watching were used less frequently (11\%) than self-report and were used in studies with smaller sample sizes $(N=10$ and $N=70)$.

The commonality in the investigations that found the largest reductions in sedentary screen time was use of electronic devices or making TV contingent on other behaviors $[49,50,53,56,65]$. To date, trials using TV time monitoring, mandatory TV devices, or contingent TV suggest reductions in TV watching of $30-90 \%$ are possible. Creating family rules that limit television viewing could have similar effects, but notable differences may exist in the child's perception of control when comparing the use of technology versus parental control. The behavioral engineering technology of the TV Allowance appears to simplify the modification of child television viewing. It puts the choice of when to watch television in the child's control, as opposed to having a rule such as no television time until homework is completed. Because the device is enforcing the TV limits, it may also eliminate conflicts between parents and children and reduce the need for disciplinary action if a child exceeds his/her TV viewing time limit [53]. However, there are some important factors to consider with these types of interventions, and further robust investigation of the longterm effectiveness and sustainability of electronic TV time monitors is necessary [57]. In regards to the devices that limited the hours of TV watching, it is not clear whether, or for how long, a reduction in TV watching will remain when these devices are removed.

In reference to contingent TV studies, using TV as a reward for physical activity seems problematic and counterintuitive if reducing sedentary screen behavior is the goal. 
Using something (i.e., TV) as a reward may contribute to the increased liking of it and actually increase its reinforcing value [75]. Rewarded behaviors are likely to be repeated, but there is little evidence that these techniques promote longterm behavior change [76]. Furthermore, there seems to be no positive outcome for promoting TV watching, so making this more reinforcing may create additional problems in the future. Also it is unknown whether the reduction in sedentary screen behaviors could have occurred without linking TV viewing to physical activity. Longer follow-up periods are needed for studies that involved contingent TV and mandatory use of an electronic TV monitoring device. Only four of the 18 interventions reevaluated the magnitude of sedentary screen behavior changes in the follow-up period after the intervention had been completed. Without followup data, the long-term sustainability of reduced sedentary screen behaviors remains questionable.

Limitations in intervention design, implementation, research design, effect moderation, target outcome, and measurement issues are all variables that could impact the success of behavior modification interventions. Very few studies reported on the fidelity of intervention delivery or receipt making it challenging to ascertain the validity of behavioral outcomes reported. These issues may compromise the internal validity of an intervention. Thus, the lack of information on fidelity of intervention delivery, and/or receipt, and the variations among studies make comparing study efficacy challenging. Additionally, many different assessment tools were used in these studies to document changes in sedentary screen behaviors. Most specifically, the difference between self-report versus objective measures makes comparing outcomes between the studies challenging. Finally, several of the studies included in this paper had small sample sizes, which potentially minimized power to find significant outcomes, and/or were of short duration, with minimal followup.

While reducing sedentary screen behaviors may have a positive impact on improving the health of children, this paper highlights the need for future research in this area. Interventions to reduce sedentary screen time need to be explored further with different age groups (children less than 6 years old, teenagers, and adults) and in various different delivery settings (pediatrician offices, schools, afterschool programs, communities, etc.). As new screen options continuously emerge (smart phones, ipads, etc.), it will be necessary to conduct comprehensive research that targets these other sedentary screen options. It is imperative that reliable and valid measurements of screen behaviors are developed and that measure all important sedentary screen time options. Finally, as screen-based behaviors appear to play a more prominent role in American's leisure time, reducing sedentary screen time alone may not be enough. Research needs to investigate ways to make sedentary screen behaviors more active.

In summary, interventions with an emphasis on reducing sedentary screen behaviors have been successful in preadolescent children. The magnitude of the significant sedentary screen behavior reductions varied greatly $(-0.44 \mathrm{~h} /$ day to $-3.1 \mathrm{~h} /$ day). Importantly, the most effective interventions for reducing sedentary screen behaviors in children focused exclusively on sedentary screen behaviors or involved tools beyond the use of behavior modification techniques. Results from these interventions also suggest that behavioral modification strategies alone may be less effective at reducing sedentary screen behaviors when sedentary screen behaviors are one of multiple health-related behaviors of interest and when sedentary screen behaviors are not the primary outcome of interest. Focusing on multiple health behaviors at once may dilute the outcomes of specific health behaviors. In several of the studies that targeted multiple health-related behaviors, sedentary screen behaviors increased or were not affected at all. Based on the results of this paper, there is a need for future research to better understand methods to more effectively reduce sedentary screen time in children.

\section{References}

[1] E. Stamatakis, M. Hamer, and D. W. Dunstan, "Screen-based entertainment time, all-cause mortality, and cardiovascular events: population-based study with ongoing mortality and hospital events follow-up," Journal of the American College of Cardiology, vol. 57, pp. 292-299, 2011.

[2] D. W. Dunstan, E. L. M. Barr, G. N. Healy et al., “Television viewing time and mortality: the australian diabetes, obesity and lifestyle study (AusDiab)," Circulation, vol. 121, no. 3, pp. 384-391, 2010.

[3] M. S. Buchowski, S. S. Cohen, C. E. Matthews et al., "Physical activity and obesity gap between black and white women in the southeastern U.S," American Journal of Preventive Medicine, vol. 39, no. 2, pp. 140-147, 2010.

[4] T. T. Fung, F. B. Hu, J. Yu et al., "Leisure-time physical activity, television watching, and plasma biomarkers of obesity and cardiovascular disease risk," American Journal of Epidemiology, vol. 152, no. 12, pp. 1171-1178, 2000.

[5] E. S. Ford, H. W. Kohl, A. H. Mokdad, and U. A. Ajani, "Sedentary behavior, physical activity, and the metabolic syndrome among U.S. adults," Obesity Research, vol. 13, no. 3, pp. 608-614, 2005.

[6] G. N. Healy, K. Wijndaele, D. W. Dunstan et al., "Objectively measured sedentary time, physical activity, and metabolic risk: the Australian diabetes, obesity and lifestyle study (AusDiab)," Diabetes Care, vol. 31, no. 2, pp. 369-371, 2008.

[7] R. W. Jakes, N. E. Day, K. T. Khaw et al., "Television viewing and low participation in vigorous recreation are independently associated with obesity and markers of cardiovascular disease risk: EPIC-Norfolk population-based study," European Journal of Clinical Nutrition, vol. 57, no. 9, pp. 1089-1096, 2003.

[8] M. T. Hamilton, D. G. Hamilton, and T. W. Zderic, "Role of low energy expenditure and sitting in obesity, metabolic syndrome, type 2 diabetes, and cardiovascular disease, and cardiovascular disease," Diabetes, vol. 56, no. 11, pp. 26552667, 2007.

[9] D. E. Feldman, T. Barnett, I. Shrier, M. Rossignol, and L. Abenhaim, "Is physical activity differentially associated with different types of sedentary pursuits?" Archives of Pediatrics and Adolescent Medicine, vol. 157, no. 8, pp. 797-802, 2003.

[10] G. N. Healy, D. W. Dunstan, J. Salmon, J. E. Shaw, P. Z. Zimmet, and N. Owen, "Television time and continuous metabolic risk in physically active adults," Medicine and Science in Sports and Exercise, vol. 40, no. 4, pp. 639-645, 2008. 
[11] V. J. Rideout, D. F. Roberts, and U. G. Foehr, Generation M2: Media in the Lives of 8- to 18-Year-Olds, Kaiser Family Foundation, Menlo Park, Calif, USA, 2005.

[12] V. J. Rideout, U. G. Foehr, and D. F. Roberts, Generation M2: Media in the Lives of 8- to 18-Year-Olds, Kaiser Family Foundation, Menlo Park, Calif, USA, 2010.

[13] S. B. Sisson, T. S. Church, C. K. Martin et al., "Profiles of sedentary behavior in children and adolescents: the US national health and nutrition examination survey, 20012006," International Journal of Pediatric Obesity, vol. 4, no. 4, pp. 353-359, 2009.

[14] R. P. Troiano, R. R. Briefel, M. D. Carroll, and K. Bialostosky, "Energy and fat intakes of children arid adolescents in the United States: data from the national health and nutrition examination surveys," American Journal of Clinical Nutrition, vol. 72, no. 5, pp. 1343S-1353S, 2000.

[15] R. E. Andersen, C. J. Crespo, S. J. Bartlett, L. J. Cheskin, and M. Pratt, "Relationship of physical activity and television watching with body weight and level of fatness among children: results from the third national health and nutrition examination survey," Journal of the American Medical Association, vol. 279, no. 12, pp. 938-942, 1998.

[16] J. C. Eisenmann, R. T. Bartee, D. T. Smith, G. J. Welk, and Q. Fu, "Combined influence of physical activity and television viewing on the risk of overweight in US youth," International Journal of Obesity, vol. 32, no. 4, pp. 613-618, 2008.

[17] C. Hume, A. Singh, J. Brug, W. Mechelen, and M. Chinapaw, "Dose-response associations between screen time and overweight among youth," International Journal of Pediatric Obesity, vol. 4, no. 1, pp. 61-64, 2009.

[18] J. P. Rey-Lopez, G. Vicente-Rodriguez, M. Biosca, and L. A. Moreno, "Sedentary behaviour and obesity development in children and adolescents," Nutrition, Metabolism and Cardiovascular Diseases, vol. 18, no. 3, pp. 242-251, 2008.

[19] C. L. Ogden, C. D. Fryar, M. D. Carroll, and K. M. Flegal, "Mean body weight, height, and body mass index, United States 1960-2002," Advance Data, no. 347, pp. 1-17, 2004.

[20] A. A. Hedley, C. L. Ogden, C. L. Johnson, M. D. Carroll, L. R. Curtin, and K. M. Flegal, "Prevalence of overweight and obesity among US children, adolescents, and adults, 19992002," Journal of the American Medical Association, vol. 291, no. 23, pp. 2847-2850, 2004.

[21] W. H. Dietz, "Health consequences of obesity in youth: childhood predictors of adult disease," Pediatrics, vol. 101, no. 3, pp. 518-525, 1998.

[22] A. Must, P. F. Jacques, G. E. Dallal, C. J. Bajema, and W. H. Dietz, "Long-term morbidity and mortality of overweight adolescents - a follow-up of the Harvard Growth Study of 1922 to 1935," The New England Journal of Medicine, vol. 327, no. 19, pp. 1350-1355, 1992.

[23] T. M. McCambridge, D. T. Bernhardt, J. S. Brenner et al., "Active healthy living: prevention of childhood obesity through increased physical activity," Pediatrics, vol. 117, no. 5, pp. 1834-1842, 2006.

[24] C. J. Crespo, E. Smit, R. P. Troiano, S. J. Bartlett, C. A. Macera, and R. E. Andersen, "Television watching, energy intake, and obesity in US children: results from the third national health and nutrition examination survey, 1988-1994," Archives of Pediatrics and Adolescent Medicine, vol. 155, no. 3, pp. 360365, 2001.

[25] L. H. Epstein, J. N. Roemmich, R. A. Paluch, and H. A. Raynor, "Influence of changes in sedentary behavior on energy and macronutrient intake in youth," American Journal of Clinical Nutrition, vol. 81, no. 2, pp. 361-366, 2005.
[26] L. H. Epstein, J. N. Roemmich, R. A. Paluch, and H. A. Raynor, "Physical activity as a substitute for sedentary behavior in youth," Annals of Behavioral Medicine, vol. 29, no. 3, pp. 200209, 2005.

[27] D. M. Williams, H. A. Raynor, and J. T. Ciccolo, "A review of TV viewing and its association with health outcomes in adults," American Journal of Lifestyle Medicine, vol. 2, pp. 1238-1245, 2008.

[28] M. S. Buchowski and M. Sun, "Energy expenditure, television viewing and obesity," International Journal of Obesity and Related Metabolic, vol. 20, pp. 236-244, 1996.

[29] L. H. Epstein and J. N. Roemmich, "Reducing sedentary behavior: role in modifying physical activity," Exercise and Sport Sciences Reviews, vol. 29, no. 3, pp. 103-108, 2001.

[30] J. Utter, D. Neumark-Sztainer, R. Jeffery, and M. Story, “Couch potatoes or French fries: are sedentary behaviors associated with body mass index, physical activity, and dietary behaviors among adolescents?" Journal of the American Dietetic Association, vol. 103, no. 10, pp. 1298-1305, 2003.

[31] K. A. Coon and K. L. Tucker, "Television and children's consumption patterns: a review of the literature," Minerva Pediatrica, vol. 54, no. 5, pp. 423-436, 2002.

[32] J. Utter, R. Scragg, and D. Schaaf, "Associations between television viewing and consumption of commonly advertised foods among New Zealand children and young adolescents," Public Health Nutrition, vol. 9, no. 5, pp. 606-612, 2006.

[33] American Academy of Pediatrics and Committee on Public Educartion, "Children, adolescents, and television," Pediatrics, vol. 107, pp. 423-426, 2001.

[34] T. Gorely, S. J. H. Biddle, S. J. Marshall, and N. Cameron, "The prevalence of leisure time sedentary behaviour and physical activity in adolescent boys: an ecological momentary assessment approach," International Journal of Pediatric Obesity, vol. 4, no. 4, pp. 289-298, 2009.

[35] T. Gorely, S. J. Marshall, S. J. H. Biddle, and N. Cameron, "The prevalence of leisure time sedentary behaviour and physical activity in adolescent girls: an ecological momentary assessment approach," International Journal of Pediatric Obesity, vol. 2, no. 4, pp. 227-234, 2007.

[36] Nielson Company Web Site, "New York (NY): The Nielson Company Television Audience 2009," http:/blog.nielsen.com nielsenwire/wp-content/uploads/2010/04/TVA_2009-for-Wire .pdf.

[37] D. F. Roberts, U. G. Foehr, V. J. Rideout, and M. Brodie, Kids and Media at the New Millennium, Kaiser Family Foundation, Menlo Park, Calif, USA, 1999.

[38] E. A. Vandewater, V. J. Rideout, E. A. Wartella, X. Huang, J. H. Lee, and M. S. Shim, "Digital childhood: electronic media and technology use among infants, toddlers, and preschoolers," Pediatrics, vol. 119, no. 5, pp. e1006-e1015, 2007.

[39] J. C. Wright, A. C. Huston, E. A. Vandewater et al., "American children's use of electronic media in 1997: a national survey," Journal of Applied Developmental Psychology, vol. 22, no. 1, pp. 31-47, 2001.

[40] R. J. Hancox, B. J. Milne, and R. Poulton, "Association between child and adolescent television viewing and adult health: a longitudinal birth cohort study," The Lancet, vol. 364, no. 9430, pp. 257-262, 2004.

[41] K. F. Janz, T. L. Burns, and S. M. Levy, "Tracking of activity and sedentary behaviors in childhood: the Iowa bone development study," American Journal of Preventive Medicine, vol. 29, no. 3, pp. 171-178, 2005.

[42] K. F. Janz, J. D. Dawson, and L. T. Mahoney, “Tracking physical fitness and physical activity from childhood to adolescence: 
the muscatine study," Medicine and Science in Sports and Exercise, vol. 32, no. 7, pp. 1250-1257, 2000.

[43] R. R. Pate, S. G. Trost, M. Dowda et al., "Tracking of physical activity, physical inactivity, and health-related physical fitness in rural youth," Pediatric Exercise Science, vol. 11, no. 4, pp. 364-376, 1999.

[44] A. E. Maloney, T. C. Bethea, K. S. Kelsey et al., "A pilot of a video game (DDR) to promote physical activity and decrease sedentary screen time," Obesity, vol. 16, no. 9, pp. 2074-2080, 2008.

[45] J. F. Sallis and N. Owen, Physical Activity and Behavioral Medicine, Sage, Thousand Oaks, Calif, USA, 1999.

[46] J. R. Sorenson and A. Steckler, "Improving the health of the public: a behavior-change perspective," Health Education Research, vol. 17, no. 5, pp. 493-494, 2002.

[47] D. Crawford and K. Ball, "Behavioural determinants of the obesity epidemic," Asia Pacific Journal of Clinical Nutrition, vol. 11, supplement 8, pp. S718-S721, 2002.

[48] S. L. Gortmaker, K. Peterson, J. Wiecha et al., "Reducing obesity via a school-based interdisciplinary intervention among youth: planet health," Archives of Pediatrics and Adolescent Medicine, vol. 153, no. 4, pp. 409-418, 1999.

[49] T. N. Robinson, "Reducing children's television viewing to prevent obesity: a randomized controlled trial," Journal of the American Medical Association, vol. 282, no. 16, pp. 1561-1567, 1999.

[50] M. S. Faith, N. Berman, M. Heo et al., "Effects of contingent television on physical activity and television viewing in obese children," Pediatrics, vol. 107, no. 5, pp. 1043-1048, 2001.

[51] B. A. Dennison, T. J. Russo, P. A. Burdick, and P. L. Jenkins, "An intervention to reduce television viewing by preschool children," Archives of Pediatrics and Adolescent Medicine, vol. 158, no. 2, pp. 170-176, 2004.

[52] S. L. Escobar-Chaves, C. M. Markham, R. C. Addy, A. Greisinger, N. G. Murray, and B. Brehm, "The fun families study: intervention to reduce children's TV viewing," Obesity, vol. 18, supplement 1, pp. S99-S101, 2010.

[53] L. H. Epstein, J. N. Roemmich, J. L. Robinson et al., “A randomized trial of the effects of reducing television viewing and computer use on body mass index in young children," Archives of Pediatrics and Adolescent Medicine, vol. 162, no. 3, pp. 239-245, 2008.

[54] B. S. Ford, T. E. McDonald, A. S. Owens, and T. N. Robinson, "Primary care interventions to reduce television viewing in African-American children," American Journal of Preventive Medicine, vol. 22, no. 2, pp. 106-109, 2002.

[55] T. N. Robinson, J. D. Killen, H. C. Kraemer et al., "Dance and reducing television viewing to prevent weight gain in AfricanAmerican girls: the Stanford GEMS pilot study," Ethnicity and Disease, vol. 13, no. 1, pp. S65-S77, 2003.

[56] M. K. Todd, M. J. Reis-Bergan, C. L. Sidman et al., "Effect of a family-based intervention on electronic media use and body composition among boys aged 8-11 years: a pilot study," Journal of Child Health Care, vol. 12, no. 4, pp. 344-358, 2008.

[57] C. Ni Mhurchu, V. Roberts, R. Maddison et al., "Effect of electronic time monitors on children's television watching: pilot trial of a home-based intervention," Preventive Medicine, vol. 49, no. 5, pp. 413-417, 2009.

[58] S. E. Whaley, S. McGregor, L. Jiang, J. Gomez, G. Harrison, and E. Jenks, "A WIC-based intervention to prevent early childhood overweight," Journal of Nutrition Education and Behavior, vol. 42, no. 3, pp. S47-S51, 2010.

[59] L. H. Epstein, R. A. Paluch, C. C. Gordy, and J. Dorn, "Decreasing sedentary behaviors in treating pediatric obesity,"
Archives of Pediatrics and Adolescent Medicine, vol. 154, no. 3, pp. 220-226, 2000.

[60] L. H. Epstein, R. A. Paluch, C. K. Kilanowski, and H. A. Raynor, "The effect of reinforcement or stimulus control to reduce sedentary behavior in the treatment of pediatric obesity," Health Psychology, vol. 23, no. 4, pp. 371-380, 2004.

[61] M. Harrison, C. F. Burns, M. McGuinness, J. Heslin, and N. M. Murphy, "Influence of a health education intervention on physical activity and screen time in primary school children: 'Switch Off-Get Active," Journal of Science and Medicine in Sport, vol. 9, no. 5, pp. 388-394, 2006.

[62] D. A. Gentile, G. Welk, J. C. Eisenmann et al., "Evaluation of a multiple ecological level child obesity prevention program: switch what you Do, View, and Chew," BMC Medicine, vol. 7, article 49, 2009.

[63] J. Salmon, K. Ball, C. Hume, M. Booth, and D. Crawford, "Outcomes of a group-randomized trial to prevent excess weight gain, reduce screen behaviours and promote physical activity in 10-year-old children: switch-play," International Journal of Obesity, vol. 32, no. 4, pp. 601-612, 2008.

[64] J. N. Roemmich, C. M. Gurgol, and L. H. Epstein, "Open-loop feedback increases physical activity of youth," Medicine and Science in Sports and Exercise, vol. 36, no. 4, pp. 668-673, 2004.

[65] G. S. Goldfield, R. Mallory, T. Parker et al., "Effects of openloop feedback on physical activity and television viewing in overweight and obese children: a randomized, controlled trial," Pediatrics, vol. 118, no. 1, pp. e157-e166, 2006.

[66] A. Gorin, H. A. Raynor, K. Chula-Maguire, and R. Wing, "Decreasing household television time: a pilot study of a combined behavioral and environmental internention," Behavioral Interventions, vol. 21, no. 4, pp. 273-280, 2006.

[67] D. Premack, "Toward empirical behavior laws: I. Positive reinforcement," Psychological Review, vol. 66, no. 4, pp. 219233,1959

[68] S. D. Stovitz and M. E. Batt, "The epidemic has gone global: can exercise is medicine help quell the tide?" British Journal of Sports Medicine, vol. 44, no. 10, p. 693, 2010.

[69] A. Bandura, Social Foundations of Thought and Action: A Social Cognitive Theory, Prentice Hall, Englewood Cliffs, NJ, USA, 1986.

[70] H. Rachlin, Judgement, Decision, and Choice: A Cognitive/ Behavioral Synthesis, W.H. Freeman, New York, NY, USA, 1989.

[71] L. H. Epstein, "Integrating theoretical approaches to promote physical activity," American Journal of Preventive Medicine, vol. 15, no. 4, pp. 257-265, 1998.

[72] J. O. Prochaska and W. F. Velicer, "The transtheoretical model of health behavior change," American Journal of Health Promotion, vol. 12, no. 1, pp. 38-48, 1997.

[73] M. J. Bryant, J. C. Lucove, K. R. Evenson, and S. Marshall, "Measurement of television viewing in children and adolescents: a systematic review," Obesity Reviews, vol. 8, no. 3, pp. 197-209, 2007.

[74] D. L. G. Borzekowski and T. N. Robinson, "Viewing the viewers: ten video cases of children's television viewing behaviors," Journal of Broadcasting and Electronic Media, vol. 43, no. 4, pp. 506-528, 1999.

[75] L. L. Birch, S. I. Zimmerman, and H. Hind, "The influence of social-affective context on the formation of children's food preferences," Child Development, vol. 51, pp. 856-861, 1980.

[76] J. I. Robison, “To reward?... or not to reward?: questioning the wisdom of using external reinforcement in health promotion programs," American Journal of Health Promotion, vol. 13, no. 1, pp. 1-3, 1998. 


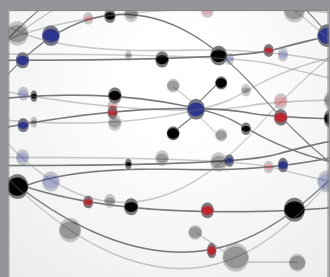

The Scientific World Journal
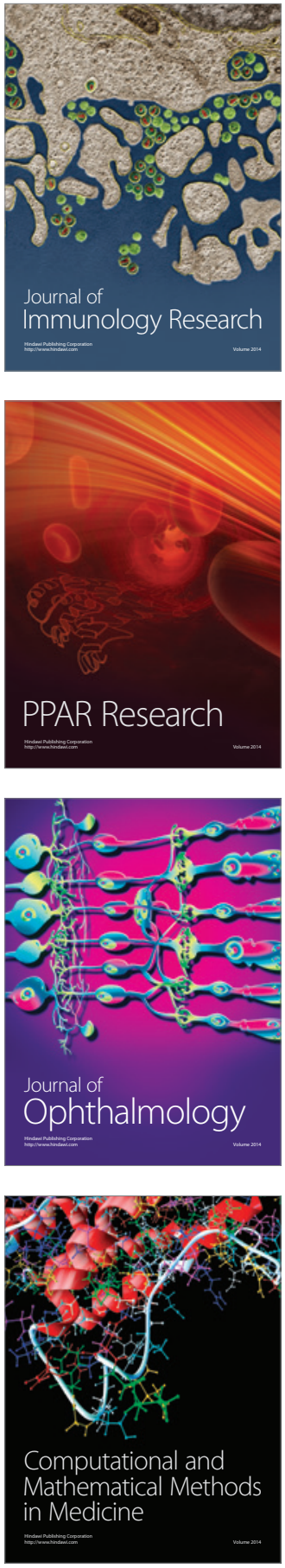

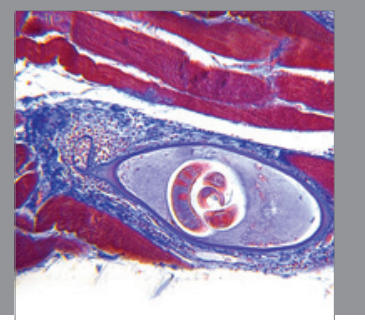

Gastroenterology

Research and Practice
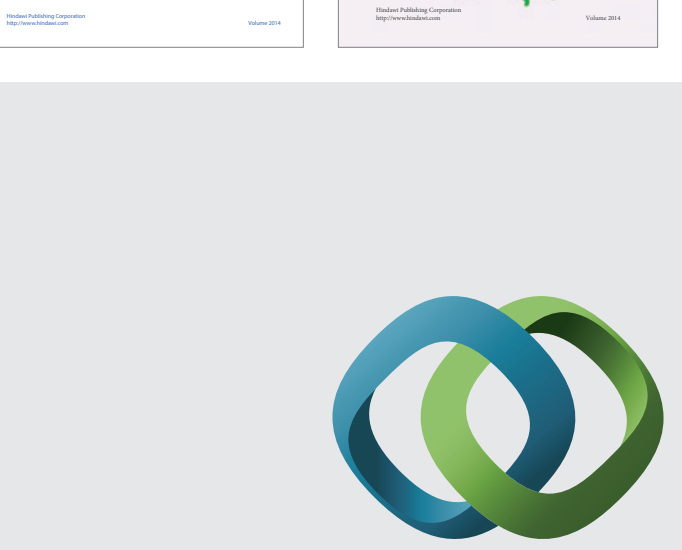

\section{Hindawi}

Submit your manuscripts at

http://www.hindawi.com
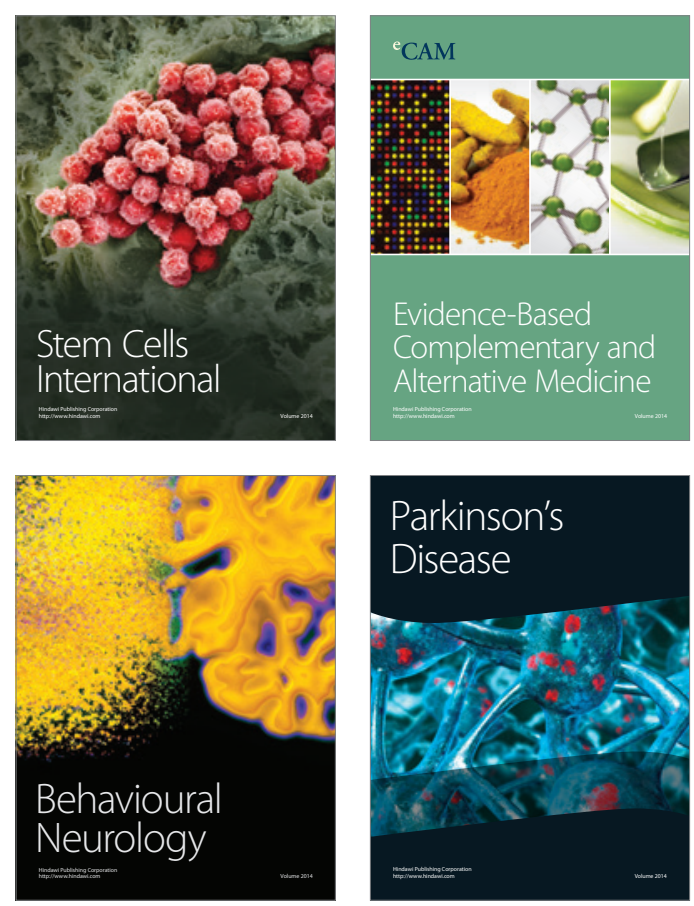

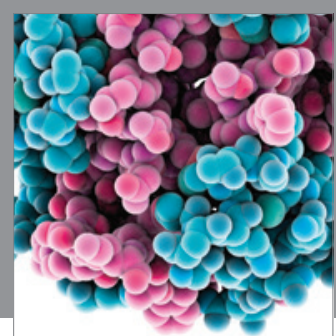

Journal of
Diabetes Research

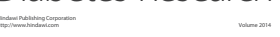

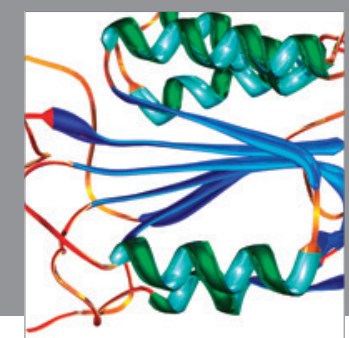

Disease Markers
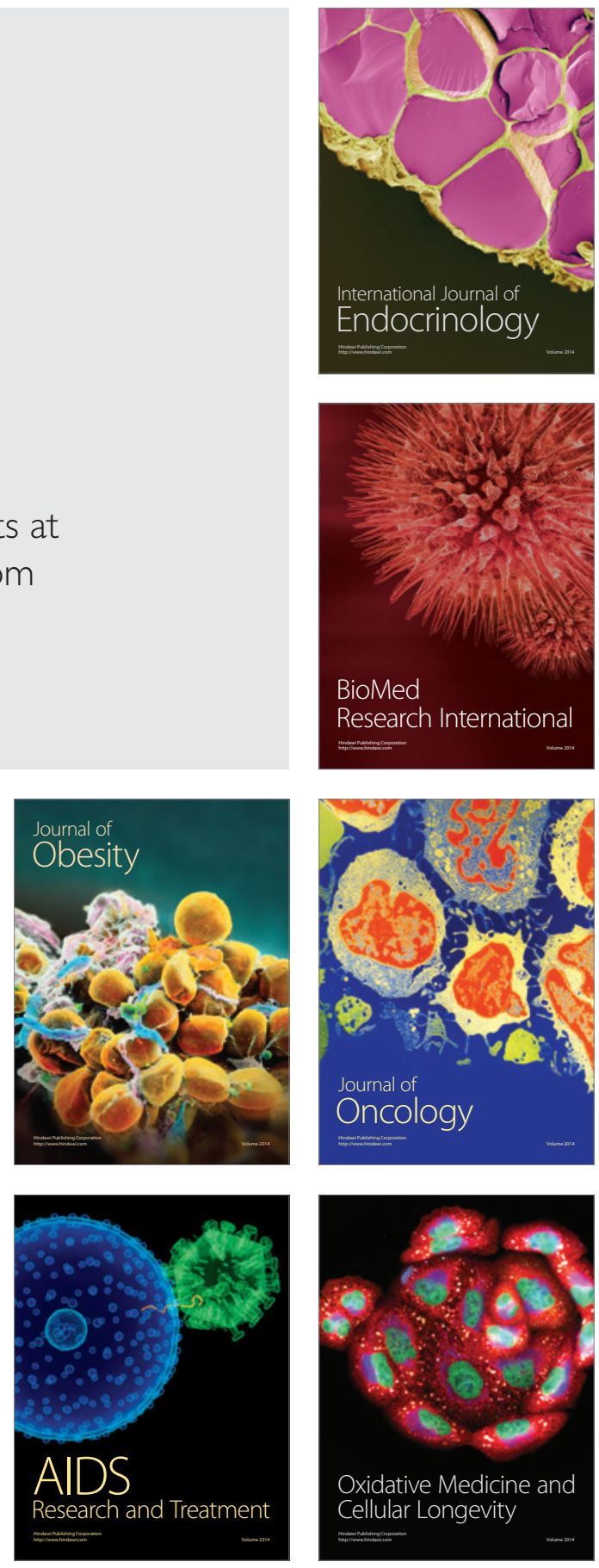